\title{
Comparision of Molecular Geometry Based On Ab Initio (HF) and DFT (B3LYP) and Thermodynamic Parameters of 2-Amino- 4-Methoxy-6-Methyl Pyrimidine
}

\author{
Lalit Kumar \\ Meerut College Meerut $(U, P)$
}

\begin{abstract}
Theoretical geometric parameters (bond lengths, bond angles and dihedral angle) were calculated using ab initio Hartree Fock $(H F)$ and density functional B3LYP method with $6-31+G(d, p)$ and 6 $31++G(d, p)$ basis set. Thermodynamic parameters such as total energy,zero-point energy, rotational constants dipole moment, thermal energy, specific heat and entropy of 2-amino-4-methoxy-6-methyl pyrimidine are calculated. The plots of thermodynamic parameters have been given in following paper.
\end{abstract}

Keywords: $H F, D F T, 2,4,6-A M M P$ etc.

\section{Introduction}

Recent spectroscopic studies of Pyrimidine and its derivatives have been motivated because of their biological and pharmaceutical importance. Pyrimidine nucleus is one of the most important heterocycles exhibiting remarkable pharmacological activities. Many pyrimidine derivatives have been developed as chemotherapeutic agents and are widely used. Pyrimidine also shows antifungal properties. Flucytosine is a fluorinated pyrimidine used as nucleosidal anti fungal agent for the treatment of serious systemic infections caused by susceptible strains of candida and Cryptococcus [1]. The pyrimidine when substituted with -OH, $\mathrm{CH}_{3}$ and $\mathrm{NH}_{2}$ gives many biological important molecules like cytosine, thyemine etc [2-5]. The analysis of vibrational spectra of the molecules might be helpful in understanding of biological processes and in the analysis of relatively complex systems. Vibrational spectroscopy has been widely used as a standard tool for structural characterization of molecular systems by HF and DFT calculations. In this paper we apply HF and DFT levels of theory using $6-31+\mathrm{G}(\mathrm{d}, \mathrm{p})$ and $6-311++\mathrm{G}(\mathrm{d}, \mathrm{p})$ basis set to optimized geometry of the titled compound and a comparision made on different basis sets.

\section{Experimental Details:}

The pure sample of compound 2-amino-4-methoxy-6-methyl pyrimidine (2, 4, 6-AMMP) was obtained from Sigma-Aldrich Chemical Company (U.S.A.) and its purity was confirmed by elemental analysis and melting point determination. Infrared spectrum of the compound was recorded on Perkin-ElmerSpectrophotometer in the region $400-4400 \mathrm{~cm}^{-1}$ in $\mathrm{KBr}$ pellets technique. Laser Raman spectrum of 2,4,6AMMP was recorded in the region $200-2000 \mathrm{~cm}^{-1}$ on Spex-Rama Lab Spectrophotometer using 52 MG ArgonKrypton laser of wave length $488 \mathrm{~nm}$. The thermodynamic parameters viz enthalpy function $\left[\mathrm{H}^{0}-\mathrm{E}_{0}^{0}\right] / \mathrm{T}$, heat capacity $\mathrm{C}_{\mathrm{P}}{ }^{0}$, free energy $\left[\mathrm{F}^{0}-\mathrm{E}_{0}^{0}\right] / \mathrm{T}$ and entropy $\mathrm{S}^{0}$ at different temperatures are calculating from rigid rotatorharmonic oscillator approximation.

\section{Computational Details}

HF and DFT calculations were performed by means of theGaussian'03 package of programs. The molecular structure of 2, 4, 6-AMMP in the ground state are optimized by HF and DFT/B3LYP with the 6$311++\mathrm{G}(\mathrm{d}, \mathrm{p})$ higher basis set. All the calculations are performed by using Gaussian 03 program package on the personal computer. Becke's three -parameters exchange functional (B3) in combination with the correlation functional of Lee, Yang and Parr (LYP) known as B3LYP. The optimized structural parameters were used in the vibrational frequency calculations at HF and DFT levels to characterize all stationary points as minima [67].

\subsection{Geometrical Parameters}

\section{Result And Discussion}

The molecular structures of 2-amino-4-methoxy-6-methyl pyrimidine (2,4,6-AMMP) having Cs symmetry are shown in Fig. 1.1. The optimized geometrical parameters (bond lengths and bond angles ) of 2,4,6-AMMP are calculated at HF/6-31+G(d,p), HF/6-311++G(d,p), B3LYP/6-31+G(d,p) and B3LYP/6$311++\mathrm{G}(\mathrm{d}, \mathrm{p})$ levels as shown in Table 1.1 and Table 1.2 respectively. 


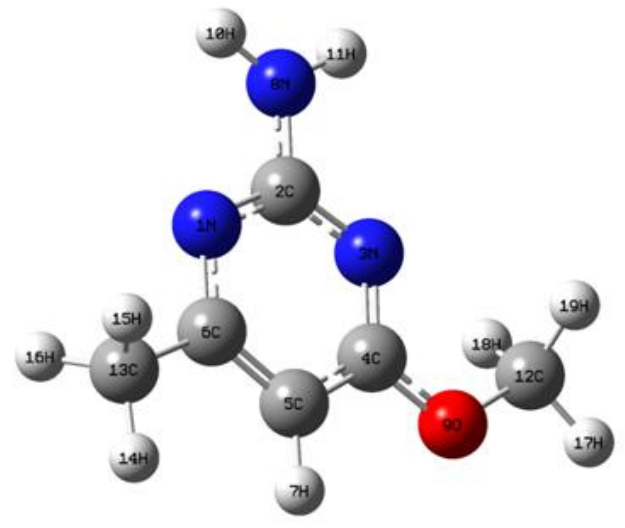

Fig. 1.1 Molecular structure of 2-amino-4-methoxy-6-methyl pyrimidine

Table 1.1: Optimized Bond Lengths of 2-amino-4-methoxy-6-methyl pyrimidine

\begin{tabular}{|c|c|c|c|c|}
\hline \multirow{2}{*}{ BOND } & \multicolumn{4}{|c|}{ Bond Lengths $\{$ Angstrom $(\mathbf{A})\}$} \\
\cline { 2 - 5 } & HF/6-31+ G(d, p) & HF/6-311++G(d, p) & $\begin{array}{c}\text { B3LYP/6 } \\
\mathbf{3 1 + G}(\mathbf{d}, \mathbf{p})\end{array}$ & B3LYP/6-311++G(d, p) \\
\hline N1-C2 & 1.3172 & 1.3144 & 1.335 & 1.3303 \\
\hline N1-C6 & 1.3354 & 1.3345 & 1.3458 & 1.3369 \\
\hline C2-N3 & 1.3364 & 1.335 & 1.3516 & 1.3419 \\
\hline C2-N8 & 1.3544 & 1.3569 & 1.3215 & 1.3486 \\
\hline N3-C4 & 1.3081 & 1.3058 & 1.3982 & 1.3164 \\
\hline C4-C5 & 1.4002 & 1.3993 & 1.3365 & 1.3941 \\
\hline C4-O9 & 1.3207 & 1.3186 & 1.3869 & 1.3327 \\
\hline C5-C6 & 1.3751 & 1.3729 & 1.0926 & 1.3819 \\
\hline C5-H7 & 1.0711 & 1.0708 & 1.4848 & 1.0905 \\
\hline C6-C13 & 1.5017 & 1.5014 & 1.0157 & 1.4816 \\
\hline N8-H10 & 0.9925 & 0.9924 & 1.0152 & 1.0142 \\
\hline N8-H11 & 0.9922 & 0.9921 & 1.4145 & 1.0136 \\
\hline O9-C12 & 1.415 & 1.4133 & 1.0991 & 1.4132 \\
\hline C12-H17 & 1.0795 & 1.0799 & 1.1039 & 1.0972 \\
\hline C12-H18 & 1.0812 & 1.0817 & 1.104 & 1.1018 \\
\hline C12-H19 & 1.0813 & 1.0818 & 1.1008 & 1.1018 \\
\hline C13-H14 & 1.0828 & 1.083 & 1.1035 & 1.0988 \\
\hline C13-H15 & 1.0845 & 1.0848 & 1.1035 & 1.1016 \\
\hline C13-H16 & 1.0844 & 1.0848 & & 1.1016 \\
\hline
\end{tabular}

It is clear from the Table 1.1 that the bond lengths for $\mathrm{C} 12-\mathrm{H} 18$ and $\mathrm{C} 12-\mathrm{H} 19$ has the same bond length of $1.1018 \AA$ at $\mathrm{B} 3 \mathrm{LYP} / 6-311++\mathrm{G}(\mathrm{d}, \mathrm{p})$ level and negligible difference of .0001 between bond lengths of $\mathrm{C} 12-\mathrm{H} 18$ and $\mathrm{C} 12-\mathrm{H} 19$ at the $\mathrm{HF} / 6-311++\mathrm{G}(\mathrm{d}, \mathrm{p})$ level. The bond lengths for $\mathrm{C} 13-\mathrm{H} 15$ and $\mathrm{C} 13-\mathrm{H} 16$ has the same bond length of $1.0848 \AA$ at the HF/6-311++G(d,p) level and 1.1016 at B3LYP/6-311++G(d,p) level. The bond angles for H14-C13-H15 and H14-C13-H15 are same i.e $109.2^{\circ}$ at the HF/6-311++G(d,p) level and $109.18^{\circ}$ at B3LYP/6-311++G(d,p) level as shown in the Table 1.2 . All the other bond lengths and bond angles are mentioned and compared in the Table 1.1 and 1.2.

Table 1.2: Optimized Bond Angles of 2-amino-4-methoxy-6-methyl pyrimidine

\begin{tabular}{|c|c|c|c|c|}
\hline \multirow{2}{*}{ BOND } & \multicolumn{4}{|c|}{ Bond angles $\left(^{\circ}\right)$} \\
\cline { 2 - 5 } & HF/6-31+G(d, p) & HF/6-311++G(d, p) & B3LYP /6-31+G(d,p) & $\begin{array}{c}\text { B3LYP /6- } \\
\text { 311++G(d,p) }\end{array}$ \\
\cline { 2 - 5 } & & 116.5628 & 116.454 & 116.468 \\
\hline C2-N1-C6 & 116.6234 & 126.5812 & 126.57 & 126.486 \\
\hline N1-C2-N3 & 126.493 & 117.4008 & 117.06 & 117.216 \\
\hline N1-C2-N8 & 117.4046 & 116.0069 & 116.368 & 116.392 \\
\hline N3-C2-N8 & 116.0935 & 115.997 & 115.576 & 115.704 \\
\hline C2-N3-C4 & 116.0163 & 122.9943 & 123.341 & 113.231 \\
\hline N3-C4-C5 & 123.0149 & 119.5936 & 118.932 & 117.981 \\
\hline N3-C4-O9 & 119.531 & 117.4121 & 117.726 & 116.086 \\
\hline C5-C4-O9 & 117.4541 & 115.7011 & 116.028 & 121.029 \\
\hline C4-C5-C6 & 115.7042 & 120.8833 & 121.083 & \\
\hline C4-C5-H7 & 120.8898 & & & \\
\hline
\end{tabular}




\begin{tabular}{|c|c|c|c|c|}
\hline C6-C5-H7 & 123.4057 & 123.4151 & 122.887 & 122.885 \\
\hline N1-C6-C5 & 122.1449 & 122.1593 & 122.032 & 122.025 \\
\hline N1-C6-C13 & 115.8711 & 115.9092 & 116.296 & 116.361 \\
\hline C5-C6-C13 & 121.9839 & 121.9315 & 121.671 & 121.615 \\
\hline C2-N8-H10 & 117.5214 & 116.968 & 118.605 & 118.629 \\
\hline C2-N8-H11 & 118.0337 & 117.4465 & 119.363 & 119.405 \\
\hline H10-N8-H11 & 118.8327 & 118.2563 & 121.56 & 121.769 \\
\hline C4-O9-C12 & 119.4453 & 119.5081 & 116.381 & 116.351 \\
\hline O9-C12-H17 & 105.2964 & 105.3908 & 105.672 & 105.668 \\
\hline O9-C12-H18 & 110.7327 & 110.8168 & 110.957 & 110.979 \\
\hline O9-C12-H19 & 110.7301 & 110.8147 & 110.961 & 110.982 \\
\hline H17-C12-H18 & 110.3606 & 110.2719 & 110.659 & 110.629 \\
\hline H17-C12-H19 & 110.3163 & 110.2223 & 110.637 & 110.612 \\
\hline H18-C12-H19 & 109.3551 & 109.2789 & 107.977 & 107.995 \\
\hline C6-C13-H14 & 111.7425 & 111.7331 & 111.977 & 111.996 \\
\hline C6-C13-H15 & 109.5407 & 109.4921 & 109.983 & 109.903 \\
\hline C6-C13-H16 & 109.5211 & 109.4713 & 109.979 & 109.901 \\
\hline H14-C13-H15 & 109.1963 & 109.2342 & 109.111 & 109.183 \\
\hline H14-C13-H16 & 109.2016 & 109.244 & 109.104 & 109.175 \\
\hline H15-C13-H16 & 107.543 & 107.5725 & 106.528 & 106.527 \\
\hline
\end{tabular}

\subsection{Thermodynamic functions}

The total thermal energy, heat capacity, entropy along with their translational, rotational and vibrational contributions are calculated. The total thermal energy calculated by HF methods are overestimated as compared to B3LYP methods. The total dipole moment is also calculated by HF and B3LYP methods. Apart from the above theoretical thermodynamic parameters, some parameters with variation of temperature have also been calculated. To calculate the thermodynamic parameters one requires the principal moments of inertia, molecular weight, temperature and the vibrational fundamentals. Thermodynamic functions of 2-amino-4methoxy-6-methyl pyrimidine have been calculated with the help of computer program at different temperatures between 200-1500 K using the experimental fundamental frequencies assuming rigid rotator-harmonic oscillator approximation [8]. The thermodynamic parameters viz enthalpy function $\left[\mathrm{H}^{0}-\mathrm{E}_{0}^{0}\right] / \mathrm{T}$, heat capacity $\mathrm{C}_{\mathrm{P}}{ }^{0}$, free energy $\left[\mathrm{F}^{0}-\mathrm{E}_{0}^{0}\right] / \mathrm{T}$ and entropy $\mathrm{S}^{0}$ at different temperatures are given in Tables 1.3 . The plots of thermodynamic parameters have been given in Fig.1.2 and it was found that the thermodynamic functions rise more rapidly in the low temperature range and less rapidly in the high temperature range.

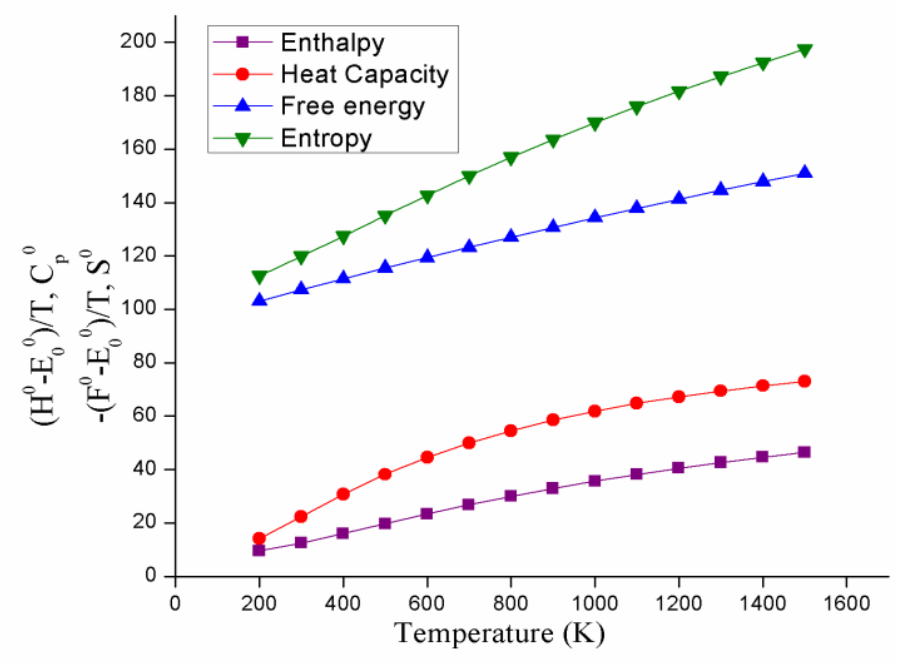

Fig. 1.2: Temperature V/s enthalpy, heat capacity, free energy and entropy of 2-amino-4-methoxy-6methyl pyrimidine

At low temperatures only translational parts of motion gives its contribution but as temperature increases rotational and vibrational motions are excited [9]. Beyond a certain value of temperature (nearly at $1400 \mathrm{~K}$ ) there is no further increase in molecular motion and therefore heat capacity becomes almost constant. 
Table 1.3: Thermodynamic Functions of 2-amino-4-methoxy-6-methyl pyrimidine (in Cal. /Mol-K)

\begin{tabular}{|c|c|c|c|c|}
\hline $\begin{array}{c}\text { Temperature } \\
\text { K } \\
\end{array}$ & Enthalpy $\quad\left(\mathbf{H}^{0}-\mathbf{E}_{0}{ }^{0}\right) / \mathrm{T}$ & Heat Capacity $C_{p}{ }^{0}$ & $\begin{array}{r}\text { Free energy } \\
\left.\mathbf{E}_{0}^{0}\right) / T\end{array}$ & $\begin{array}{ll}\text { Entropy } & S^{0}\end{array}$ \\
\hline 200 & 9.58 & 14.23 & 103.03 & 112.61 \\
\hline 300 & 12.46 & 22.39 & 107.43 & 119.89 \\
\hline 400 & 15.99 & 30.71 & 111.49 & 127.48 \\
\hline 500 & 19.70 & 38.18 & 115.46 & 135.16 \\
\hline 600 & 23.33 & 44.57 & 119.37 & 142.70 \\
\hline 700 & 26.76 & 49.98 & 123.23 & 149.99 \\
\hline 800 & 29.96 & 54.57 & 127.01 & 156.97 \\
\hline 900 & 32.92 & 58.49 & 130.72 & 163.63 \\
\hline 1000 & 35.65 & 61.87 & 134.33 & 169.97 \\
\hline 1100 & 38.17 & 64.78 & 137.84 & 176.01 \\
\hline 1200 & 40.49 & 67.30 & 141.27 & 181.76 \\
\hline 1300 & 42.64 & 69.49 & 144.59 & 187.23 \\
\hline 1400 & 44.63 & 71.41 & 147.83 & 192.45 \\
\hline 1500 & 46.47 & 73.09 & 150.97 & 197.44 \\
\hline
\end{tabular}

\section{Conclusion}

The structural parameters bond lengths and bond angles were determined and analysed both at HF and DFT levels of theory. Most of the bond lengths, bond angles and dihedral angles have same value in all four $\mathrm{HF} / 6-31+\mathrm{G}(\mathrm{d}, \mathrm{p}), \mathrm{HF} / 6-311++\mathrm{G}(\mathrm{d}, \mathrm{p}), \mathrm{B} 3 \mathrm{LYP} / 6-311++\mathrm{G}(\mathrm{d}, \mathrm{p})$ and B3LYP/6-311++G(d,p) basis sets. The thermodynamic parameters viz enthalpy function $\left[\mathrm{H}^{0}-\mathrm{E}_{0}^{0}\right] / \mathrm{T}$, heat capacity $\mathrm{C}_{\mathrm{P}}{ }^{0}$, free energy $\left[\mathrm{F}^{0}-\mathrm{E}_{0}^{0}\right] / \mathrm{Tand}^{0}$ entropy $\mathrm{S}^{0}$ at different temperatures are in good agreement with standard results.

11] Polak \& H.J. Scholer, Chemotherapy; 1975; 21; 113.

[2] R.E. Handshumacher \& A.D. Welch, "The nucleic acids" (Academic Press, New York) 1960.

[3] R.C. Lord \& J.G. Thomas Jr., Spectrochimica Acta, 23(A), 2551 (1967).

[4] V.K. Rastogi, Y.C. Sharma, S. N. Sharma, R.E. Hester Eds. \& R.B. Girling (Royal Soc. of CHem.) 403 (1991)

[5] T. Shimanguchi, M. Tsuboind Y.Kyogobu, Adv. Chem. Phys. (Inter Science, New York) 7(P), 435 (1964).

[6] C. Lee, W. Yang, and R. G. Parr, Physical Review B, 37 (1998) 785.

[7] J. B. Foresman and M. J. Frisch, "Exploring Chemistry with Electronic Structure Methods", Second edition, Gaussian Inc., Pittsburgh, PA, 1996.

[8] M. L. Strekalov, Chemical Physics, 355 (2009) 62.

[9] J.M. Seddon and J. D. Gale, "Thermodynamics and Statistical Mechanics", (Royal Society of Chemistry, London), (2001) 98. 